\title{
EDITORIAL
}

\section{REVISIÓN INTEGRATIVA DE LA INVESTIGACIÓN EN ENFERMERÍA, EL RIGOR CIENTÍFICO QUE SE LE EXIGE}

\author{
Maria da Graça Oliveira CROSSETTI ${ }^{\mathrm{a}}$
}

Iniciativas recientes y visibles en el desarrollo de la práctica de enfermería con base en evidencias, han orientado la necesidad de los enfermeros en consumir y producir conocimientos específicos inherentes a la naturaleza de su trabajo en diferentes contextos profesionales. Producciones resultantes de procedimientos metodológicos diversos con destaque, en el momento, para las revisiones sistemáticas de la literatura cuyo fundamento teórico metodológico por sí sólo, ofrece conocimientos profundos y exhaustivo con relación a un determinado fenómeno en estudio posibilitando al enfermero decidir por la mejor conducta a ser tomada. Dentro de estos enfoques el resultado es la Revisión Integral (RI) de investigación, que de modo creciente ha sido aplicada en la producción científica en la enfermería en diferentes niveles tales como en el desarrollo de trabajos de conclusión de curso, monografías, disertaciones y tesis. Hecho que se atestigua con el creciente volumen de artículos que aplicaron esta metodología, sometidos y publicados en periódicos nacionales e internacionales. No es raro constatar que el investigador menos experimentado usa los términos revisión integral, revisión de la literatura, revisión sistemática y metaanálisis como sinónimos ${ }^{(1)}$. Aunque haya algunas similitudes estas metodologías son diferentes, pues tienen procedimientos distintos que conducen al alcance de objetivos y consecuentes resultados igualmente distintos. La revisión de la literatura se estructura en resúmenes críticos de estudios sobre un tópico de interés buscando contextualizar el problema de investigación; se restringe a estudios relevantes que apunten para nuevos datos relacionados a los objetivos de la investigación. En esta revisión la actualización temporal de las referencias es el punto crucial del rigor científico. La revisión sistemática se caracteriza por evidencias de investigaciones cuidadosamente sintetizadas aplicadas para responder a las cuestiones enfocadas en la práctica clínica; es conducida exclusivamente a partir de riguroso proceso de selección y análisis de varias producciones sobre el problema en estudio. El metaanálisis es una metodología que cuantitativamente integra y verifica la asociación de los resultados de múltiples estudios recientes, sobre un determinado evento de la práctica clínica. La revisión integral sintetiza resultados de pesquisas anteriores, o sea, ya realizadas y muestra sobre todo las conclusiones del corpus de la literatura sobre un fenómeno específico, abarca pues, todos los estudios relacionados a la cuestión guía que orienta la búsqueda de esta literatura. Los datos resumidos y comparados permiten que se obtengan conclusiones generales sobre el problema de investigación. Sigue un proceso de análisis sistemático y sumariado de la literatura, lo que sí es bien conducido califica sus resultados lo que posibilita identificar las lagunas del conocimiento con relación al fenómeno en estudio, identificar la necesidad de futuras investigaciones, revelar cuestiones centrales del área en enfoque, identificar marcos conceptuales o teóricos, mostrar el estado del arte de la producción científica resultante de investigaciones sobre un determinado tema. En la conducción de la RI el investigador debe responder a las siguientes preguntas al evaluar el conocimiento ya producido, a saber: ¿Qué es lo que sabe? ¿Cuál es la calidad de lo que se sabe? ¿Qué se debe saber? ¿Cuál es el próximo paso para la investigación o práctica ${ }^{(2) ?}$

La revisión integral de literatura de investigación en enfermería ha sido propuesta por diferentes autores cuyos procedimientos metodológicos se diferencian en el numero de etapas y en la forma como proponen desarrollarlas y presentarlas. Sin embargo el proceso sigue básicamente cinco etapas: 1) formulación del problema, 2) recolección de datos o definiciones sobre la búsqueda de la literatura, 3) evaluación de los datos, 4) análisis de los datos y 5) presentación e interpretación de los resultados ${ }^{(1,3,4,5)}$. La RI bien conducida se caracteriza por la criticidad propia de las investigaciones primarias en lo que se refiere a replica, claridad y rigor científico. Así uno de los aspectos fundamentales a ser considerado por el investigador es el tamaño de la muestra, o sea, la búsqueda de la literatura

a Profesor Titular del departamento de Enfermería Médico Quirúrgica de la Escuela de Enfermería de la UFRGS Coordinadora de la Comisión Editorial de la Revista Gaúcha de Enfermagem. 


\section{EDITORIAL}

deberá ser exhaustiva. Lo que significa que podrá abarcar la búsqueda de artículos de investigación de hace 20 a 30 años o más para encontrar los orígenes de la práctica con relación al fenómeno en estudio. La relación de los artículos estará completa cuando haya saturación de los datos, lo que se identifica a partir del momento en que al verificarla se constata que cada uno dona artículos y los autores son familiares a los investigadores, o a partir del momento en que se observa que los datos se caracterizan por un determinado estándar lo que expresa la conclusión natural de la revisión integral de la literatura ${ }^{(2)}$.

El informe final de la RI para publicación no debe ser presentado como una serie de sumarios o resúmenes, pero contemplar la integración de conceptos, pensamientos, definiciones o de otras informaciones relevantes propia de los autores cuyas producciones fueron objetos de evaluación. Lo que significa que el enfoque del informe serán los resultados y consecuentes conclusiones derivados del análisis y discusión de las informaciones extraídas de los artículos resultantes de las investigaciones analizadas en respuesta a los objetivos o la cuestión guía del estudio.

RI de la literatura, en la investigación al fundamentarse en el rigor científico exigido para otros enfoques de investigación, representa un recurso más para la construcción del conocimiento en enfermería y dada su naturaleza puede subsidiar el desarrollo y la precisión de la práctica clínica y consecuentes intervenciones que tengan como resultados la seguridad del paciente.

\section{REFERENCIAS}

1 Cooper HM. The integrative research review: a systematic approach. Beverly Hills: Sage 1984

2 Russel CL. An overwiew of the integrative research review. Progress in Transplantion. Missouri: Columbia; 2005.

3 Whittemore R, Knafl K. The integrative review: updated methodology. J Adv Nurs. 2005;52(5):546-53.

4. Ganong LH. Integrative reviews of nursing research. Res Nurs Health. 1987;10(1):1-11.

5 Broome ME. Integrative literature reviews for the development of concepts. In: Rodgers BL, Knafl KA, organizador. Concept development in nursing: foundations, techniques and applications. Philadelphia: W.B. Saunders Company; 2000. p.231-50. 